\title{
Can the R.E.N.A.L Nephrometry Score Preoperatively Predict Postoperative Clinical Outcomes in Patients Undergoing Open and Laparoscopic Partial Nephrectomy?
}

\author{
Stella Roushias ${ }^{\mathrm{a}} \quad$ Nikhil Vasdev $^{\mathrm{a}} \quad$ Bhaskar Ganai $^{\mathrm{b}} \quad$ Sebastian Mafeld $^{\mathrm{b}}$ \\ David Rix ${ }^{a} \quad$ David Thomas ${ }^{a} \quad$ Naeem Soomro ${ }^{a}$ \\ Department of a Urology and ${ }^{\mathrm{b}}$ Radiology, Freeman Hospital, Newcastle upon Tyne, UK
}

\author{
Key Words \\ Partial nephrectomy • RENAL score
}

\begin{abstract}
Aim: We evaluate whether the preoperative R.E.N.A.L Nephrometry Score (RNS) can predict the postoperative outcomes in patients undergoing either an open or laparoscopic partial nephrectomy. Patients and Methods: We retrospectively calculated the RNS of 128 patients who underwent either an open partial nephrectomy (OPN) $(n=38)$ or laparoscopic partial nephrectomy $(\mathrm{LPN})(n=90)$ between 2003 and 2011. Patients were categorized into low, moderate or high complexity groups based on RNSs. Intra-operative warm ischemic time (WIT), peri-operative surgical outcomes using the Clavien-Dindo classification, postoperative histology, positive surgical margin rates were correlated to the RNS. Results: The RNS was associated with the length of the WIT in OPN (low vs. moderate vs. high: 11.4 vs. 13.1 vs. 23.4 minutes, $p=0.025$ ) and blood loss in LPN (low vs. moderate 319 vs. $498 \mathrm{ml}, \mathrm{p}=0.009$ ). The positive surgical margins were greater in high versus moderate RNS lesions (40 vs. $7.4 \%, p=0.045)$. No differences were seen in complications, hospital stay or transfusion rates. The RNS was significantly higher in OPN versus LPN (7.45 vs. 6.2, $p=0.0002)$. Conclusion: An Increasing RNS was associated with increased WIT in OPN and blood loss in LPN, supporting RNS relationship to tumor complexity. A higher RNS in OPN indicate it may corroborate procedure choice. RNS should allow comparisons
\end{abstract}

\section{KARGER}

Fax +4161306 1234

E-Mail karger@karger.ch

www.karger.com
(C) 2013 S. Karger AG, Basel

$1015-9770 / 13 / 0072-0090 \$ 38.00 / 0$

Accessible online at:

www.karger.com/cur between treatment modalities for similar complexity lesions and with further research could aid stratification of individual risk preoperatively.

Copyright $\odot 2013$ S. Karger AG, Basel

\section{Introduction}

The incidence of renal cell carcinoma is increasing worldwide with a rise of more than $2 \%$ annually [1-4]. This may be due to an increase in routine radiological imaging for investigation of abdominal pain, resulting in $>60 \%$ of tumors being detected incidentally as small renal masses $(\mathrm{T} 1 \mathrm{a}<4 \mathrm{~cm})$ on CT scan [5-7].

The recommended management of T1a tumors has evolved significantly over recent decades with partial nephrectomy being offered to suitable patients with small renal tumors, as per European Association of Urology and the National Institute for Health and Clinical Excellence guidelines $[8,9]$. In current clinical practice the absolute indication of a partial nephrectomy include solitary kidney and bilateral synchronous tumors; relative indications include unilateral mass with preoperative risk for future renal impairment (e.g. Von Hippel-Lindau disease) and tumors less than $4 \mathrm{~cm}$. A laparoscopic partial nephrectomy (LPN) has a higher complication rate 
Table 1. The RNS categorization (2009) [17]

\begin{tabular}{|c|c|c|c|}
\hline Anatomical features & \multicolumn{3}{|c|}{ Score } \\
\hline Exophytic properties & $\leq 50 \%$ & $>50 \%$ & entirely endophytic \\
\hline $\begin{array}{l}\text { Nearness of tumor to collecting } \\
\text { system or sinus }(\mathrm{mm})\end{array}$ & $\geq 7$ & $>4,<7$ & $\leq 4$ \\
\hline
\end{tabular}

Sum of 4-6 =Low complexity; 7-9 = moderate complexity; 10 high complexity.

compared to open radical nephrectomy, varying between 5.5 and $38 \%$ [10]. This is in part attributable to risk of urinary fistula $(4.4 \%)$ and technical difficulty [11]. Current literature indicated that a LPN remains underused worldwide $[12,13]$, but specialist centers are progressing quickly towards minimally invasive (laparoscopic and robotic) partial nephrectomy [14].

The current advantages of a LPN over open partial nephrectomy (OPN) include reduced blood loss, shorter total operation time, shorter hospital stay, reduced analgesic requirement and avoidance of morbidity related to large flank incisions $[5,15]$. The oncological outcomes of both an OPN and LPN are currently comparable [16]. In certain situations the disadvantages of a LPN include a restricted exposure and intricate suturing, resulting in more difficult hemostasis and urinary system closure, longer warm ischemia time (WIT) all resulting in a higher per-operative complication rate [5]. Improvements in LPN have encouraged operations on more challenging tumors $[5,15]$.

In current literature there are no randomized controlled trials comparing active surveillance, LPN, OPN, radio frequency ablation or cryotherapy in the management of small renal masses. Inconsistencies in preoperative anatomical reporting and complications to date have hindered comparative studies and moreover the decision-making process for operative approach not clearly defined. It is now thought that a through preoperative anatomical scoring system will facilitate comparisons between treatment options for patients with small renal masses and strengthen the rationale behind procedure choice and predict postoperative outcome. The R.E.N.A.L Nephrometry Score (RNS) is based on 5 reproducible and salient features related to diagnosed tumor preoperative [17] (table 1). However, results have been variable with respect to RNS as a predictor of outcomes. We evaluate whether the preoperative RNS can aid urologist in recommending either an OPN or LPN in patients being considered for partial nephrectomy.

\section{Patients and Methods}

From 2003 t 2011, 195 patients underwent OPN or LPN at our center. CTs were retrievable in 128 patients (90 LPN, 38 LPN). The remainder of the 67 patients were excluded as no preoperative imaging could be archived for the purpose of this study. On obtaining patient records and preoperative imaging the preoperative patient data was recorded, including patient age, previous renal surgery, creatinine and presenting complaint. Intra-operative data included WIT, total operation time and blood loss. Postoperative outcomes evaluated were transfusion rates, complications, length of hospital stay, surgical margins, histology, postoperative creatinine and recurrence. All patients underwent a transperitoneal LPN and OPN in our cohort. A total of 11 patients had single kidney (5 OPN and 6 LPN).

Preoperative CT was evaluated by a single radiologist. Total RNS sum was calculated and complexity category assigned: 4-6 low complexity; 7-9 moderate complexity; 10 high complexity. Complications were categorised into main urological complications and by Clavien-Dindo classification.

Statistical analysis compared low, moderate and high complexity groups using Kruskall Wallis and Mann Whitney-U non-parametric tests for numerical variables. Chi-squared and 
Fisher's exact test were used for frequency distributions. RNS as a predictor of outcomes was then evaluated for open and laparoscopic groups separately. Where outcomes correlated to RNS group, linear regression was performed based on numerical value of RNS. Laparoscopic and open RNS were compared using 2 tailed T-test. Statistical analysis was performed using Excel 2003 with Analyse-It software.

\section{Results}

Patients were categorized into complexity groups: 55 (43\%) low complexity (RNS 5-6); 68 (53.1\%) moderate complexity (RNS 7-9); 5 (3.9\%) high complexity (RNS 10). No LPNs were performed on high complexity lesions. The breakdown of open, laparoscopic and RNS category is shown in figure 1 . The mean follow-up is 52 months (range 6-110 months) for the current cohort of all patients.

Tumor diameter and Individual RNS components are shown in table 2 , represented by 'mean $\pm 95 \%$ CI (confidence interval) (median)'. Each component significantly differed between groups, indicating all contributed to tumor stratification. Although mean diameter differed between groups, median R score was 1 for all groups, as anticipated given partial nephrectomies are generally performed on small tumors.

RNS and Partial Nephrectomy Combined Outcomes

Outcomes of all partial nephrectomy are summarised in table 3 displayed as 'mean \pm standard error, (median)'. $P$ values $<0.05$ were considered significant.

RNS category was not significantly associated with operation time, blood loss, WIT, hospital stay, transfusion rates, or complications in the combined LPN/OPN group. Creatinine change was associated with increasing RNS group, but this was not sustained on high-low or high-moderate comparison. Blood loss was significantly higher in the moderate compared to low complexity group (493.7 vs. $315.6 \mathrm{ml}, \mathrm{p}=0.03$ ). Positive margins were significantly higher in the high RNS than moderate RNS group (40 vs. $7.4 \%, \mathrm{p}=0.045$ ). Operation time trend was reversed: shorter in high complexity lesions, though must be interpreted with caution given low numbers in the high RNS category.

Complications were categorised further into urological complications and Clavien-Dindo classification as shown in table 4. Overall complications occurred in $25.8 \%$ of cases $-17.4 \%$ major and $9.4 \%$ minor.

Mean RNS did not differ between cases with complications and those without (6.45 vs. $6.6, \mathrm{p}=0.58)$. Mean
RNS for those with major complications did not differ to RNS for minor/no complications (6.76 vs. 6.53, p $=0.65)$. Urine leak occurred in 5 patients $(3.9 \%), 3$ of which were LPNs and 2 OPNs. Completion nephrectomy was necessary in 1 patient, hemicolectomy/splenectomy in another, 2 required stenting/draining and 1 managed conservatively. Mean RNS ( $\pm 95 \% \mathrm{CI}$; median) of those with leak versus no leak was $7.4( \pm 2.9 ; 8)$ versus $6.54( \pm$ $0.29 ; 7)$ which did not reach significance.

\section{RNS Category and Tumor Pathology}

Distribution of pathology can be viewed in figure 2 . Histology was missing for 1 high and 1 moderate complexity lesion. Benign tumors occurred in $10.9 \%$ low complexity RNS, 3.4\% moderate and 25\% high complexity lesions $(\mathrm{p}=0.12)$. High grade cancer appeared to increase with RNS, but this was insignificant: $14.6 \mathrm{vs}$. 26.3 vs. $33 \%$ low vs. moderate vs. high complexity lesions $(\mathrm{p}=0.3)$.

\section{LPN Outcomes}

LPN outcomes analysed separately are summarised in table 5. In this subgroup no high complexity lesions were operated on. A significant difference was demonstrated between blood loss, but not other outcomes.

\section{OPN Results}

Results are summarised in table 6. In this subgroup WIT differed significantly: 11.4 vs. 13.1 vs. 23.4 minutes $(\mathrm{p}=0.025)$. This difference was sustained between low-high and moderate-high groups, but not between low-moderate groups. On linear regression RNS was significantly correlated to WIT $(\mathrm{p}<0.001)$. No other variables differed significantly between the groups.

\section{RNS and Procedure Choice}

Distribution of complexity categories was significantly different between LPN and OPN ( $\mathrm{p}=0.0002)$ : low complexity tumors accounted for $23.7 \%$ OPN vs. $51 \%$ LPN; moderate tumors $63.2 \%$ OPN vs. $49 \%$ LPN; high complexity tumours $13.2 \%$ OPNs vs. $0 \%$ LPNs. Mean RNS was significantly lower in LPN than OPN RNS (6.2 \pm 0.3 vs. $7.45 \pm 0.6, \mathrm{p}=0.0002$ ).

\section{Discussion}

Early comparative studies between treatment modalities used anatomical parameters such as tumor size and polar location. The RNS is intended to record salient an- 


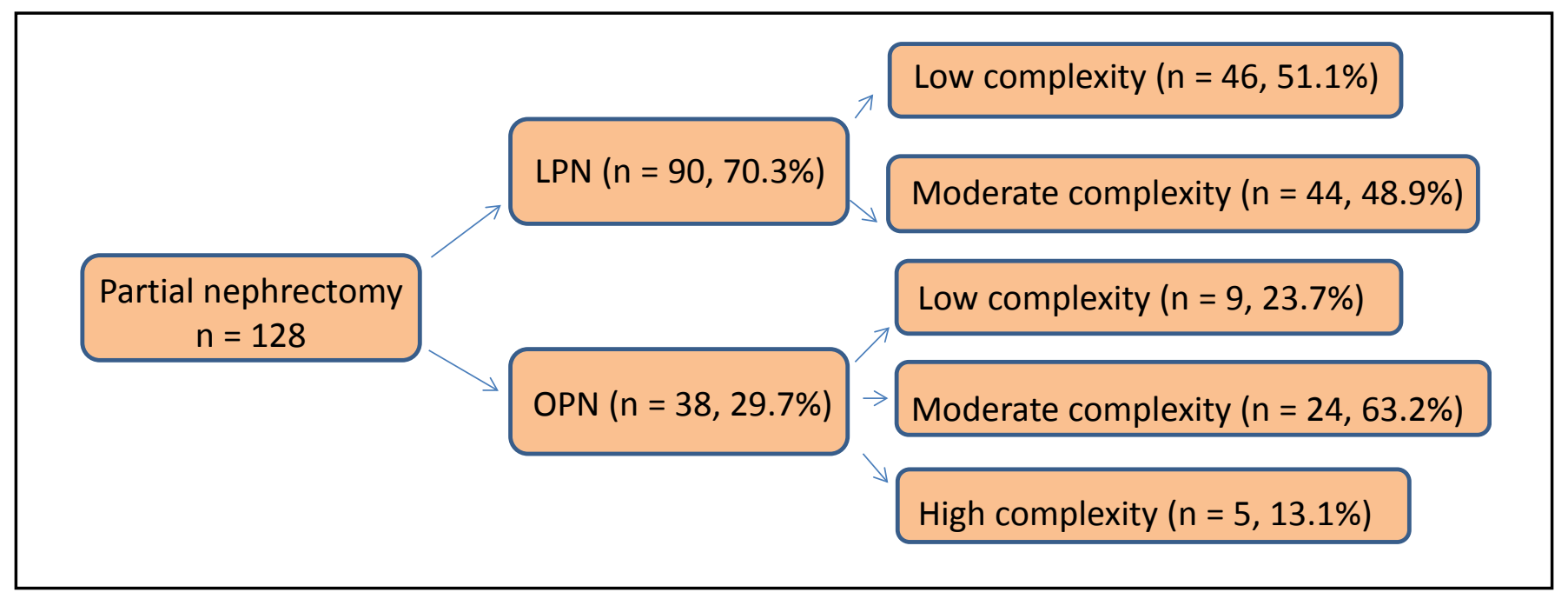

Fig. 1. Flow diagram of procedure breakdown and complexity categories.

Table 2. Individual RNS scored variables

\begin{tabular}{|c|c|c|c|c|}
\hline & Low $(n=55)$ & Moderate $(n=68)$ & High $(n=5)$ & $\mathrm{p}$ \\
\hline Diameter (mm) & $26.8 \pm 1.8(27)$ & $33 \pm 3.51(30)$ & $38.6 \pm 28.9(32)$ & 0.008 \\
\hline RNS sum & $5.01 \pm 0.22$ & $7.6 \pm 0.19(7)$ & $10 \pm 0(10)$ & $<0.001$ \\
\hline Radius score & $1.05 \pm 0.06(1)$ & $1.25 \pm 0.12(1)$ & $1.4 \pm 1.11$ & 0.02 \\
\hline Exophytic score & $1.27 \pm 0.12$ & $1.79 \pm 0.14(2)$ & $2.6 \pm 1.11$ & $<0.001$ \\
\hline Nearness score & $1.4 \pm 0.18$ & $2.68 \pm 0.15$ & $3 \pm 0$ & $<0.001$ \\
\hline Location score & $1.31 \pm 0.16$ & $1.94 \pm 0.27(2)$ & $3 \pm 0(3)$ & $<0.001$ \\
\hline
\end{tabular}

Single number in parentheses of the boxes is the median value.

Table 3. Individual RNS scored variables

\begin{tabular}{|c|c|c|c|c|c|c|c|}
\hline & $\begin{array}{l}\text { Low RNS } \\
(\mathrm{n}=55)\end{array}$ & $\begin{array}{l}\text { Moderate RNS } \\
(n=68)\end{array}$ & $\begin{array}{l}\text { High RNS } \\
(n=5)\end{array}$ & $\mathrm{p}$ & $\begin{array}{l}\text { Low-mod- } \\
\text { erate } p\end{array}$ & $\begin{array}{l}\text { Moderate-high } \\
\mathrm{p}\end{array}$ & $\begin{array}{l}\text { Low- } \\
\text { high p }\end{array}$ \\
\hline Operation time (minute) & $147.2 \pm 7.1(147.5)$ & $144.7 \pm 5.3(135)$ & $105 \pm 10(100)$ & 0.08 & 0.88 & 0.03 & 0.03 \\
\hline Blood loss (ml) & $315.6 \pm 52.1(200)$ & $493.7 \pm 63(350)$ & $246 \pm 90(180)$ & 0.07 & 0.03 & 0.3 & 0.8 \\
\hline WIT (minute) & $19.2 \pm 1.1(18)$ & $20.4 \pm 1.3(19)$ & $23.4 \pm 4.2(19)$ & 0.61 & 0.56 & 0.48 & 0.38 \\
\hline Hospital stay (day) & $6.8 \pm 0.56(6)$ & $8.3 \pm 0.9(6)$ & $8 \pm 1.8(7)$ & 0.51 & 0.41 & 0.5 & 0.34 \\
\hline Positive margins (\%) & 10.9 & 7.4 & 40 & 0.16 & 0.54 & 0.045 & 0.085 \\
\hline
\end{tabular}

Single number in parentheses of the boxes is the median value. 
Table 4. Complications by RNS category

\begin{tabular}{lllrr}
\hline & Low & Moderate & High & p \\
\hline All complications & $29 \%$ & $22 \%$ & $20 \%$ & 0.65 \\
Major complications & $20 \%$ & $19.3 \%$ & $20 \%$ & 0.97 \\
Urine leak & $3.6 \%$ & $2.9 \%$ & $20 \%$ & 0.16 \\
Pseudoaneurysm & $5.45 \%$ & $7.35 \%$ & $0 \%$ & 0.76 \\
\hline
\end{tabular}

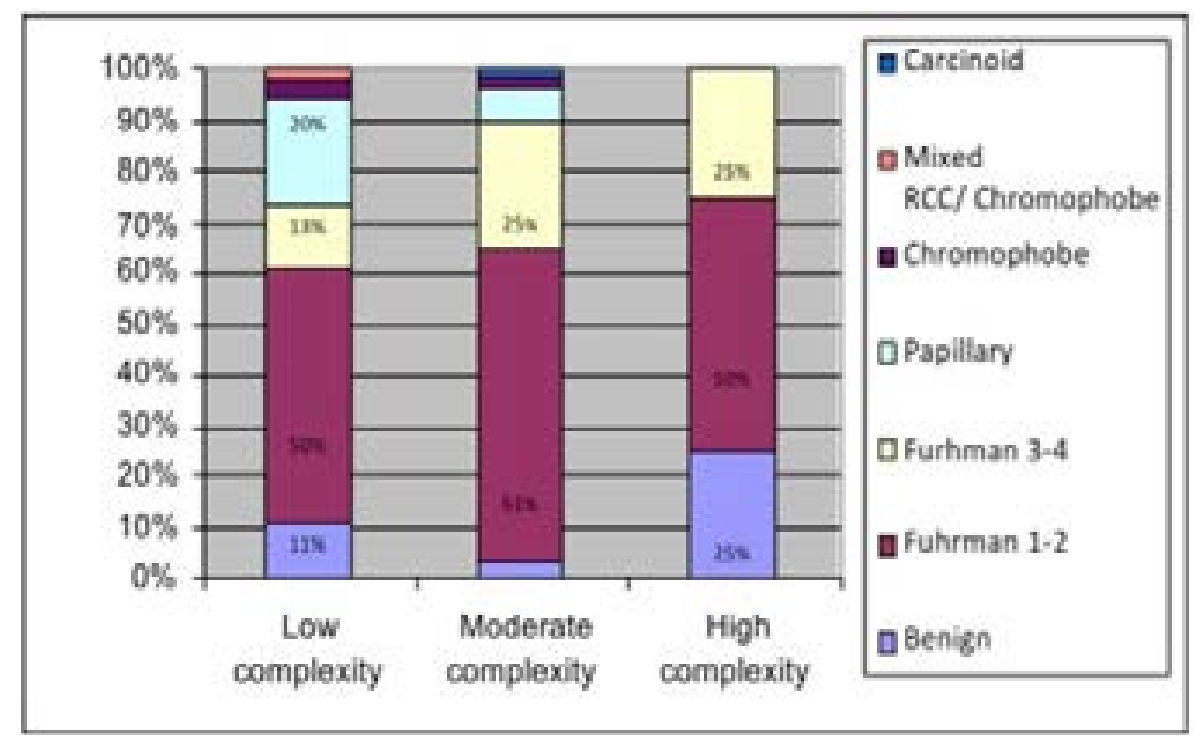

Fig. 2. Individual RNS scored variables.

Table 5. LPN outcomes

\begin{tabular}{llll}
\hline & Low RNS $(\mathrm{n}=46)$ & Moderate RNS $(\mathrm{n}=44)$ & $\mathrm{p}$ \\
\hline Operation time (minute) & $153 \pm 7.72(150)$ & $151 \pm 5.56(145)$ & 0.96 \\
Blood loss (ml) & $319.22 \pm 58.45(200)$ & $498.14 \pm 62.3(400)$ & 0.009 \\
WIT (minute) & $20.7 \pm 1.09(19)$ & $23.6 \pm 1.55(23.5)$ & 0.1 \\
Hospital stay (day) & $6.71 \pm 0.64(6)$ & $6.48 \pm 0.49(5.5)$ & 0.92 \\
Transfusion rate (\%) & 4.35 & 18.9 & 0.62 \\
All complications $(\%)$ & 24.3 & 2.3 & 0.86 \\
Urine leak (\%) & 4.3 & 4.5 & 1 \\
Pseudoaneurysm (\%) & 8.7 & $13 \pm 11$ & 0.72 \\
Creatinine change (\%) & $-3 \pm 0.5$ & 4.5 & 0.1 \\
Positive margins (\%) & 8.76 & 0.67 \\
\hline
\end{tabular}

Single number in parentheses of the boxes is the median value. 
Table 6. OPN outcomes

\begin{tabular}{|c|c|c|c|c|c|c|c|}
\hline & $\begin{array}{l}\text { Low RNS } \\
(\mathrm{n}=55)\end{array}$ & $\begin{array}{l}\text { Moderate RNS } \\
(\mathrm{n}=68)\end{array}$ & $\begin{array}{l}\text { High RNS } \\
(\mathrm{n}=5)\end{array}$ & $\mathrm{p}$ & $\begin{array}{l}\text { Low-mod- } \\
\text { erate } p\end{array}$ & $\begin{array}{l}\text { Moderate-high } \\
\mathrm{p}\end{array}$ & $\begin{array}{l}\text { Low- } \\
\text { high p }\end{array}$ \\
\hline Operation time (min) & $112.5 \pm 12.5(100)$ & $130 \pm 11.3(120)$ & $105 \pm 10(100)$ & 0.51 & 0.36 & 0.36 & 0.94 \\
\hline Blood loss (ml) & $292 \pm 101(150)$ & $456 \pm 158(180)$ & $246 \pm 90(180)$ & 0.96 & 0.85 & 0.91 & 0.87 \\
\hline WIT (minute) & $11.4 \pm 2.3(11.5)$ & $13.1 \pm 1.2(14)$ & $23.4 \pm 4.2(19)$ & 0.025 & 0.27 & 0.023 & 0.019 \\
\hline Hospital stay (day) & $7.25 \pm 0.84(7)$ & $11.87 \pm 2.3(8)$ & $8 \pm 1.78(7)$ & 0.76 & 0.46 & 0.78 & 0.93 \\
\hline Transfusion rate & $11 \%$ & $12.5 \%$ & $0 \%$ & 0.71 & - & - & - \\
\hline All complications & $33 \%$ & $33 \%$ & $20 \%$ & 0.83 & - & - & - \\
\hline Urine leak & $0 \%$ & $4.3 \%$ & $20 \%$ & 0.25 & - & - & - \\
\hline Pseudoaneurysm & $0 \%$ & $12.5 \%$ & $0 \%$ & 0.39 & - & - & - \\
\hline Creatinine change $(\%)$ & $12.3 \pm 19.2(0)$ & $26.6 \pm 12.6(10)$ & $-1.6 \pm 14(-4)$ & 0.29 & 0.26 & 0.25 & 0.92 \\
\hline Positive margins (\%) & 22.2 & 12.5 & 40 & 0.33 & 0.6 & 0.13 & 0.54 \\
\hline
\end{tabular}

Single number in parentheses of the boxes is the median value.

atomical features associated with resection difficulty to produce a score which corresponds to tumor complexity. Having been validated as reproducible [18], several studies have emerged demonstrating its variable prediction of complications and outcomes [19-22].

In our study RNS association to outcomes was modest. RNS was significantly associated with blood loss in LPN (and pairwise low-moderate in combined partial nephrectomy), WIT in OPN and positive margin rates. Positive margins were similar between low and moderate groups but significantly different between moderate-high and nearing significance low-high suggesting scores

10 are most predictive and differentiation between low-moderate less important. Similarly, within the OPN group, WIT was not statistically significant between the low-moderate groups suggesting high complexity scores are more predictive for longer WIT.

Widely varying complication rates of partial nephrectomy have been documented between 5.5 and 38\% [10]. Risk factors for complications include prolonged WIT, higher blood loss, tumor location and solitary kidneys $[11,19]$. Urological complications include urinary leak, perinephric hemorrhage and renal impairment. Complications arose in $25.8 \%$ of our cases, with urine leak rates $3.9 \%$, comparable to contemporary series [10]. No differences were seen between complexity groups or between RNS and major complications, contrary to that previously described by the RNS founders [20], although not proven universally [21].

The Fox Chase Cancer Center (founders of RNS) showed significant differences in major complication rates (11.5\%): 6.4 vs. 11.1 vs. $21.9 \%$ (low vs. moderate vs. high, $\mathrm{p}=0.009)$ in 390 robotic $(55.4 \%)$ and open (44.6\%) partial nephrectomy [20]. Of note, this study had a larger proportion of high (16.4\%) and moderate (55.6\%) lesions. Genitourinary complications including urinary leak ( $1.8 \%$ low, $10.1 \%$ moderate, $28 \%$ high; overall $10.8 \%$ ) differed significantly $(\mathrm{p}<0.0001)$, but these appear rather high leak rates. Estimated blood loss and WIT differed significantly between the high-low/ moderate groups. On multivariable logistic regression, operative time and high tumor complexity (RNS 10-12) were associated with major complication, odds ratio of the latter 5.4, CI: 1.2-24.2.

External validation has not been uniform. Positive results were reported by Bruner et al. [22] in a study of urine leak in 1,075 partial nephrectomise and $2.9 \%$ developed clinically significant urine leak, with a $35 \%$ increased odds for each unit increase in RNS. Of the individual components, location was found to have a reverse association i.e. polar location was associated with higher leak rates, raising the possibility this RNS component may not accurately assess tumor complexity. Those with urine leak also had longer hospital stay (6.8 vs. 4.4 days, $\mathrm{p}=0.019)$ and higher complication rates compared to case-matched controls: haemorrhage $(9.7$ vs. $1.6 \%, \mathrm{p}=$ $0.05)$; any complication $(48.4$ vs. $22 \%, \mathrm{p}<0.001)$. The authors did not stratify results into low/moderate/high RNS categories and so is unclear whether these categories are usefully assigned. Hew et al. [23] also described RNS correlation with complications (RNS $>9$, odds ratio $4.21, \mathrm{p}=0.02$ ) and was strongly predictive of WIT 
( $\mathrm{p}<0.001)$. However, only RNS $>9$ was a significant predictor, indicating little benefit of stratifying low and intermediate groups.

Hayn et al. [21] reported less convincing results in 159 consecutive LPNs. As in our study, only small numbers were high complexity lesions (30\% low, 65\% moderate, $5 \%$ high). Complication rates did not differ. Blood loss increased with RNS complexity category $(\mathrm{p}<0.034)$, but no difference reported in transfusion rates. In agreement with the Fox Chaser study, longer WIT was seen in the higher complexity groups (16 vs. 23 vs. 31 minutes, p < 0.001 ), but this did not equate to any difference in GFR. Similarly, Okhunov et al. [18] associated RNS with WIT and change in creatinine level in $101 \mathrm{LPNs}$, but again no significant difference existed between complications, operative time or bloods loss. Murfarrij et al. [24] found no differences in blood loss, operation time, hospital stay, GFR or complications in 92 robotic partial nephrectomise. However, the proportion of low complexity tumors was relatively high.

When comparing studies supportive of RNS as a predictor of complications to those showing no association, there are no definitive influencing factors. Patient cohort ages appear similar, varying distribution of low/moderate/high lesions appear in both situations and operative approach variable. Interestingly, the studies with only robotic or laparoscopic cases did not support RNS as a predictor of complications, although these had low percentage of high RNS (about 5 vs. 16.4\%, Simham et al. [20]).

Despite disparity in correlation to other outcomes, RNS association with WIT, a key step in the operation, would support its relationship to tumor complexity. High RNS appears more predictive than moderate/low RNS, indicating studies may not show significance dependent on caseload complexity. This, however, raises the issue of cut-offs for the moderate and low groups and their role where the majority of subjects fall into these categories.

Positive margins in the present study appear high at 9.4\% (18.4\% open, $6.67 \%)$ compared to other studies' about $0-5 \%[5,15]$. However, there was only 1 definite recurrence within the positive margin group who had a history of left radical nephrectomy and radiotherapy for cerebral metastases, hence a high-risk patient. With such discrepancy in positive margin: recurrence rates, our figures are possibly due to classification and local pathological analysis.

Several papers have assessed RNS relationship to procedure choice, comparing radical to partial nephrectomy and also laparoscopic approaches [25-27]. As expected in our study, OPN had higher RNS sum than LPN, in keeping with RNS use in stratifying tumour complexity.

Limitations exist within the present study. The time interval of 8 years may have created inaccuracies with learning curve dynamics and change in techniques. Three surgeons performed procedures, with possibly differing complication rates - operations were not analysed separately as greater numbers would have been required to provide adequate power. Finally, grouping LPN and OPN together may have skewed results and hence both were evaluated separately - unfortunately this led to small sample sizes. Previous studies have shown most positive results in high RNS category - given we had only 5 high complexity masses, significant differences may have been missed. In our study, the individual component of the RNS has not been correlated to evaluate outcomes in neither the OPN nor LPN group.

\section{Conclusions}

RNS offers a reproducible standardising anatomical reporting system. Although RNS correlation to operative outcomes is variable, the association with WIT supports its relationship to tumor complexity. RNS should allow for plausible comparisons between treatment modalities, particularly as more challenging tumours are operated on by laparoscopic and robotic partial nephrectomy. Further research into RNS as a predictive tool and as part of useable nomograms is required. Ideally this anatomical scoring tool could aid stratification of individual risk preoperatively, corroborate procedure choice and allow comparisons between treatment modalities for similar complexity lesions. 


\section{References}

1 Cancer trends in England and Wales, 1950- 11 Cutress ML, Ratan HL, Williams ST, O’Brien 1995. SMPS no. 66. Office for National Statistics, viewed 18/11/2011. http://www.ons. gov.uk/ons/rel/cancer-unit/cancer-trends-inengland-and-wales/smps-no--66/index.html.

-2 Chow WH, Devesa SS, Warren JL, Fraumeni JF Jr: Rising incidence of renal cell cancer in the United States. JAMA 1999;281:16281631.

-3 Jemal A, Tiwari RC, Murray T Ghafoor A, Samuels A, Ward E, Feuer EJ, Thun MJ: Cancer statistics. CA Cancer J Clin 2004;54:829.

-4 Chawla SN, Crispen PL, Hanlon AL, Greenberg RE, Chen DY, Uzzo RG: The natural history of observed enhancing renal masses: meta-analysis and review of the world literature. J Urol 2006;175:425-431.

5 Aron M, Haber GP, Gill IS: Laparoscopic partial nephrectomy. BJU Int 2007;99:12581263.

-6 Luciani LG, Cestari R, Tallarigo C: Incidental renal cell carcinoma-age and stage characterization and clinical implications: study of 1092 patients (1982-1997). Urology 2000; 56:58-62.

7 Parsons JK, Schoenberg MS, Carter HB: Incidental renal tumours: casting doubt on the efficacy of early intervention. Urology 2001; 57:1013-1015.

8 Ljungberg B, Cowan NC, Hanbury DC, Hora M, Kuczyk MA, Merseburger AS, Patard JJ, Mulders PF, Sinescu IC: EUA guidelines on renal cell carcinoma: the 2010 update. Eur Urol 2010;58:398-406.

9 Laparoscopic partial nephrectomy, IPG151, January 2006, National Institute for Health and Clinical Excellence guidelines, http:// www.guidance.nice.org.uk/IPG151.

10 Dominguez-Escrig JL, Vasdev N, O'Riordon A, Soomro N: Laparoscopic partial nephrectomy: technical considerations and an update. J Minim Access Surg 2011;7:205-221.
MF: Update on the management of T1 renal cortical tumours. BJU Int 2010;106:1130 1136.

12 Kim SP, Shah ND, Weight CJ, Thompson RH, Moriarty JP, Shippee ND, Costello BA, Boorjian SA, Leibovich BC: Contemporary trends in nephrectomy for renal cell carcinoma in the United States: results from a population based cohort. J Urol 2011;186:1779-1785.

13 Satasivam P, Rajarubendra N, Chia PH, Munshey A, Sengupta S, Bolton D: Trends in the use of nephron-sparing surgery (NSS) at an Australian tertiary referral centre: an analysis of surgical decision-making using the R.E.N.A.L. nephrometry scoring system. BJU Int 2012;109:1341-1344.

14 Gill IS, Desai MM, Kaouk JH, Meraney AM, Murphy DP, Sung GT, Novick AC: Laparoscopic partial nephrectomy for renal tumor: duplicating open surgical techniques. J Urol 2002;167:469-477.

$>15$ Oakley NE, Hegarty NJ, McNeill A, Gill IS: Minimally invasive nephron-sparing surgery for renal cell cancer. BJU Int 2006;98:278284.

16 Frank I, Blute ML, Cheville JC, Lohse CM, Weaver AL, Zincke H: Solid renal tumors: an analysis of pathological features related to tumor size. J Urol 2003;170:2217-2220.

17 KutiKov A, Uzzo RG: The R.E.N.A.L. nephrometry score: a comprehensive standardized system for quantitating renal tumor size, location and depth. J Urol 2009;182:844 -853 .

18 Okhunov Z, Rais-Bahrami S, George AK, Waingankar N, Duty B, Montag S, Rosen L, Sunday S, Vira MA, Kavoussi LR: The comparison of three renal tumor scoring systems: C-Index, P.A.D.U.A., and R.E.N.A.L. nephrometry scores. J Endourol 2011;25: 1921-1924.

19 Turna B, Frota R, Kamoi K, Lin YC, Aron M, Desai MM, Kaouk JH, Gill IS: Risk factor analysis of postoperative complications in laparoscopic partial nephrectomy. J Urol 2008;179:1289-1294.
20 Simhan J, Smaldone MC, Tsai KJ, Canter DJ, Li T, Kutikov A, Viterbo R, Chen DY, Greenberg RE, Uzzo RG: Objective measures of renal mass anatomic complexity predict rates of major complications following partial nephrectomy. Eur Urol 2011;60:724-730.

21 Hayn MH, Schwaab T, Underwood W, Kim HL: RENAL nephrometry score predicts surgical outcomes of laparoscopic partial nephrectomy. BJU Int 2011;108:876-881.

22 Bruner B, Breau RH, Lohse CM, Leibovich BC, Blute ML: Renal nephrometry score is associated with urine leak after partial nephrectomy. BJU Int 2011;108:67-72.

23 Hew MN, Baseskioglu B, Barwari K, Axwijk PH, Can C, Horenblas S, Bex A, Rosette JJ, Pes MM: Critical appraisal of the PADUA classification and assessment of the R.E.N.A.L nephrometry score in patients undergoing partial nephrectomy. J Urol 2011; 186:42-46.

24 Mufarrij PW, Krane LS, Rajamahanty S, Hemal AK: Does nephrometry scoring of renal tumors predict outcomes in patients selected for robot-assisted partial nephrectomy? J Endourol 2011;25:1649-1653.

25 Canter D, Kutikov A, Manley B, Egleston B, Simhan J, Smaldone M, Teper E, Viterbo R, Chen DY, Greenberg RE, Uzzo RG: Utility of R.E.N.A.L nephrometry scoring system in objectifying treatment decision-making of the enhancing renal mass. J Urol 2011;78: 1089-1094.

26 Rosevear HM, Gellhaus PT, Lightfoot AJ, Kresowik TP, Joudi FN, Tracy CR: Utility of RENAL nephrometry scoring system in the real world: predicting surgeon operative preference and complication risk. BJU Int 2012; 109:700-705.

27 Broughton GJ, Clark PE, Barocas DA, Cookson MS, Smith JA Jr, Herrell SD, Chang SS: Tumour size, tumour complexity, and surgical approach are associated with nephrectomy type in small renal cortical rumours treated electively. BJU Int 2012;109:1607-1613. 